\title{
Child Trafficking: A Concept Analysis
}

\author{
Amanda E. West ${ }^{1}$ \\ ${ }^{1}$ College of Social Work, University of Kentucky, Lexington, KY, USA \\ Correspondence: Amanda West, College of Social Work, University of Kentucky, 661 Patterson Office Tower, \\ Lexington, KY 40506, USA.
}

Received: February 25, 2016

Accepted: March 28, 2016

Available online: March 29, 2016

doi:10.11114/ijsss.v4i5.1407

URL: http://dx.doi.org/10.11114/ijsss.v4i5.1407

\begin{abstract}
Child trafficking is often intertwined within the public discussion of human trafficking as owning the same properties and attributes as adults who are trafficked. Yet, as the concept of trafficking is inductively explored with the specific focus related to children and youth, the published literature provides us with an increased understanding of the unique qualities that not only create an at-risk population of youth, but the descriptors of trafficking's effect on children as its own population of victims. This article follows an evolutionary analytical process in its inductive exploration of the holistic understanding of child trafficking through a systematic search of the current literature. Through a qualitative examination of the literature, surrogate terms, attributes, antecedents, and consequences and their associated themes are identified and discussed. Finally, a theoretical definition of the concept of child trafficking is provided for the examination and discussion of continued theoretical development.
\end{abstract}

Keywords: concept analysis, child trafficking, human trafficking, qualitative

\section{Introduction}

There has been increasing social awareness and academic attention on the issue of child trafficking. Nevertheless, the literature lacks an exploration of the concept of child trafficking. Therefore, using an inductive, evolutionary method of concept analysis, the researcher investigates the meaning of child trafficking within the context of the current social science literature. Concept analysis is the primary building block for the continuation of meaningful research and the development of theory (Botes, 2002). Specifically, a concept analysis is needed for a holistic understanding of child trafficking at a foundational level as a means to proceed with theoretically informed empirical research.

Estimates indicate that there are 27 million victims of overall human trafficking in existence, with the vast majority of these victims' being women and children (Jordan, Patel, \& Rapp, 2013). Child trafficking, or the trafficking of individuals under the age of 18, includes activities such as domestic labor, hard labor, and sex trafficking and is believed to involve 1.2 million children each year (International Labour Organization, 2002). While these concepts are not new to the current body of knowledge, they are only now evoking a response not only from local communities but from policymakers as well. A shared understanding of the concept as a whole can inform discussions, the development of interventions, and policy and research alike.

Anti-trafficking child advocates hope that, as awareness of child trafficking increases, both social and legal interventions will increase as well. In the United States, for example, new laws, referred to as Safe Harbor laws, are being created in at least 31 states (NCSL, 2014). These laws automatically treat children engaged in trafficking situations as victims of child sex trafficking, rather than criminals, which destigmatizes victims and can afford them treatment and services otherwise not available through a criminal setting (Bergman, 2012). This example shows how language and its associated meanings have the capacity to alter a victim's treatment course and life trajectory. The concept analysis in this paper not only concerns the many components connected to child trafficking but, more importantly, also provides a shared understanding of the concept of child trafficking. It is hoped that, through a common understanding of child trafficking, multidisciplinary fields can more effectively communicate and organize efforts to help the victims of child trafficking.

\section{Method}

This concept analysis utilizes a dispositional view in which meaning is found in the use of words. Words do not possess a meaning in and of themselves; rather, meaning is formed in the usage of the words (Baldwin, 2008). Baldwin 
explained that concepts are to be viewed as expressed abstractions repeated in social interactions with which common attributes begin to be associated. To provide a dispositional, rather than an entity view which would treat concepts as "things", Rodgers' evolutionary method of concept analysis was employed.

The evolutionary method of analysis includes the identification of a concept and surrogate terms, identifying an appropriate setting and sample for data collection, collection of data, analysis of the data, the identification of an exemplar of the concept, if needed, and implications for future development of the concept (Rodgers, 2000). According to Rodgers:

In the evolutionary approach, the emphasis is on the inductive inquiry and rigorous analysis, rather than beginning the investigation with the researcher's own preconceived ideas of the concept ... it represents the radical departure from other approaches ... in this approach concepts are not seen as static, timeless entities with identifiable boundaries ... the results do not reveal precisely what a concept is or is not . . it is consistent with the idea of a cycle providing the clarity necessary to create a foundation for further inquiry and development. (p. 84)

\subsection{Concept Identification}

The concept of child trafficking may be understood differently in different settings and through a diverse number of disciplines with differing attributes and lenses. Rodgers (2000) stated, "A concept is not a word, but the idea or characteristics associated with the word. Words are used to express concepts; they are not the concepts themselves" ( $p$. 85). Likewise, a concept is a label that is used to convey specific meaning (Baldwin, 2008). The literature on the concept of child trafficking contains surrogate terms such as child slavery, commercial sexual exploitation of children, child abuse, and child prostitution, and the choice of appropriate search terms is especially important when beginning an analysis.

\subsection{Searching the Literature}

In this research, the "setting" is characterized by the time period in which the literature search was conducted and by the disciplines chosen for exploration of the topic of child trafficking and further concept construction. Scholarly literature in law, psychology, and social work, fields that address various aspects of child trafficking, was identified for the years 2003 to 2013. The search was further defined by the use of Legal Collection and PsycINFO databases. The search terms utilized included child trafficking, child slavery, domestic minor sex trafficking, and commercial sexual exploitation of children. These search terms were chosen based upon their use in the scientific literature and in seminal pieces of work in the field of child trafficking.

During a systematic search of the literature, 70 articles were identified within the specified databases (Figure 1). Rodgers (2000) suggests retrieving at least 30 articles from the sample or $20 \%$ of the total population, whichever is greater, to ensure that the resulting data reflect a sample of diverse information. To further develop the sample from the 70 articles, article abstracts were scanned for the originally specified search terms. A random number generator was then used, as needed, to further narrow the sample size. While reviewing the identified sample, attention was paid to surrogate terms, contextual uses of the concept, and related concept attributes (Figure 2).

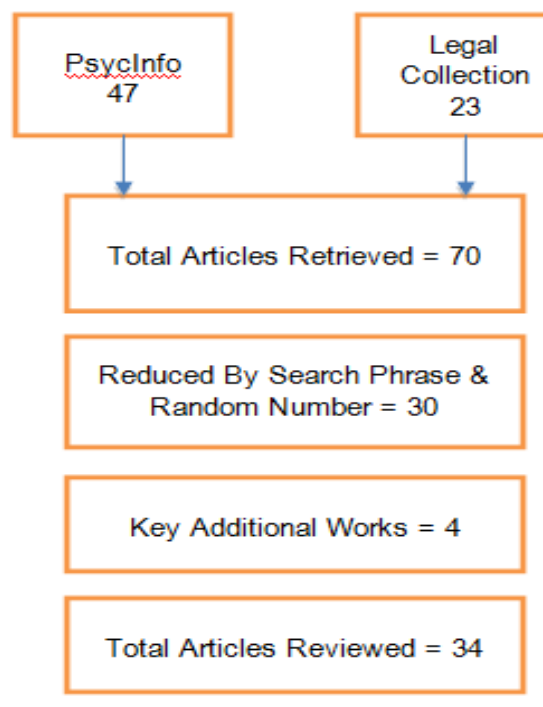

Figure 1. Flow of the search process. 


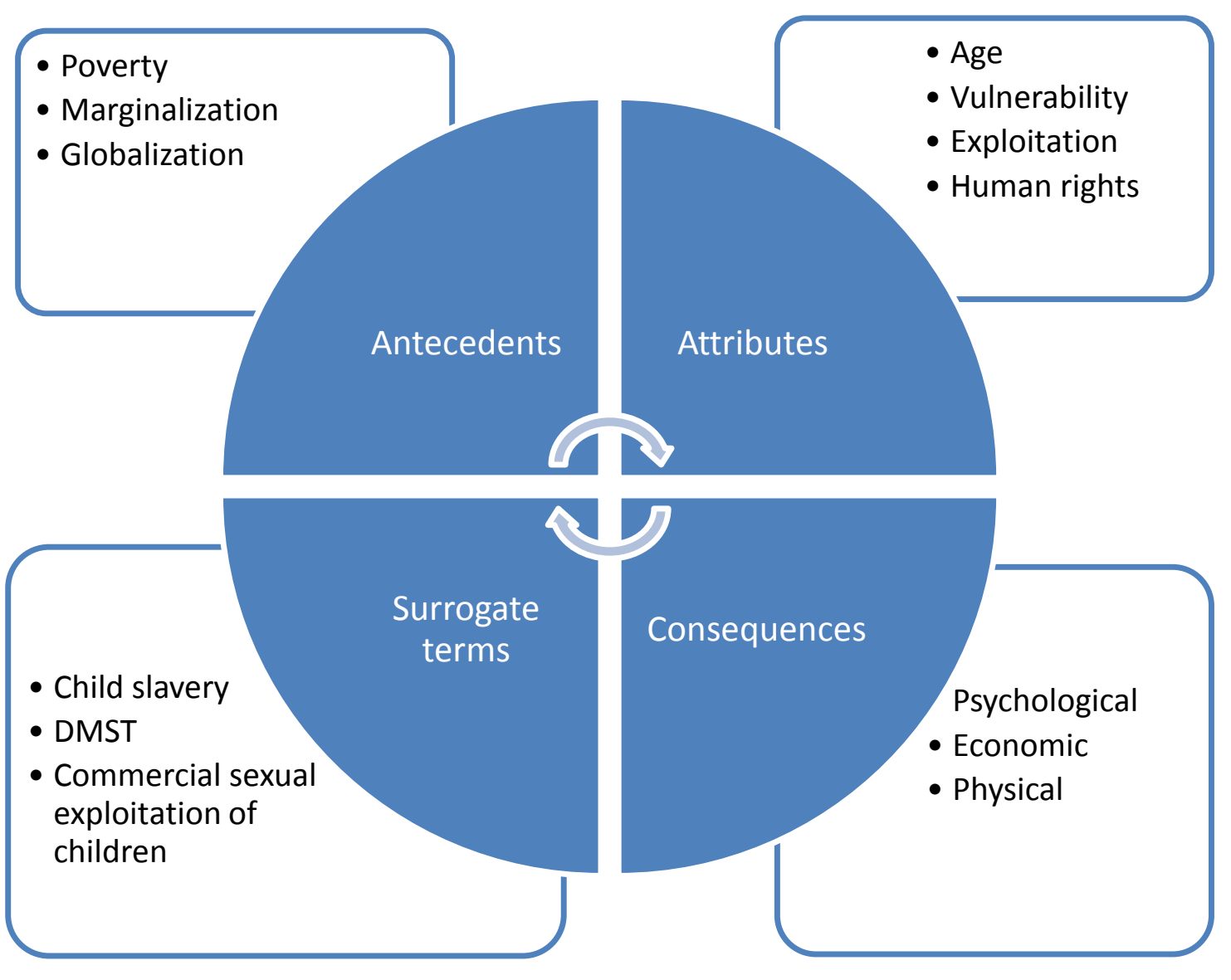

Figure 2. Antecedents, attributes, consequences, and surrogate terms.

A total of 30 articles were initially reviewed, as $20 \%$ of the sample would have been smaller than the ideal of 30 . An additional 4 articles were added to the review as Rodgers (2000) suggests the inclusion of landmark or commonly cited works, as well, and, as a result, this study included works by Estes and Weiner (2001), Goździak (2008), Logan and Hunt (2009), and Miko and Park (2002), for a total of 34 articles. The literature search included articles within a 10 year span from 2003 to 2013, and was limited to those pieces written in English. Foreign manuscripts, or manuscripts produced outside of the United States, represented countries such as Benin, Canada, Tanzania, Kenya, and West Africa.

In the literature, the terms conceptual and empirical are not mutually exclusive, and the large majority of the literature comprised conceptual articles, few of which had an empirical framework. The few empirical studies in the sample consisted of exploratory qualitative studies and one of the few quantitative reports on commercial sexual exploitation of children. Further, the literature sample represented a variety of work related to the fields of law, public health, nursing, criminology, social work, and psychology.

\section{Results}

Among the diverse terms associated with the concept of child trafficking were common terms that indicated that child trafficking was illegal, immoral, and common. There was a greater focus on the sex trafficking of children than other forms of trafficking, such as labor trafficking of children. In following the evolutionary method for concept analysis, there are four distinct categories that were addressed in the analysis of the characteristics of child trafficking: surrogate terms, attributes, antecedents, and consequences. Surrogate terms are alternative words that communicate the very same meaning as child trafficking. Attributes in this case are items or characteristics that can be used to describe key elements of child trafficking. Antecedents refer to the conditions and environment that leads to child trafficking. Finally, consequences are the conditions and environment created as a result of child trafficking.

\subsection{Surrogate Terms}

The literature indicated that surrogate terms are used to indicate the concept of child trafficking. Surrogate terms are 
different from related concepts, which may reference the concept but are not directly used with the same attributes (Rodgers, 2000). Therefore, a surrogate term can be interpreted as a replacement for the concept of child trafficking. Surrogate terms used for child trafficking included child slavery, domestic minor sex trafficking, and commercial sexual exploitation of children. These three terms were used interchangeably in the literature to express the same ideas and attributes assigned to child trafficking. While related concepts, including child abuse, exploitation, smuggling, and child labor were used, their use occurred only in reference to child trafficking rather than serving as surrogate terms.

\subsection{Attributes}

The literature also revealed that a common definition for child trafficking was not consistently used within the specified time period. The likely cause of the lack of a common definition, as well as a variety of foci, was that the scholarly and practical works were written by a diverse group of authors, both domestic and foreign. For example, an article on the cultural components of child labor in countries in Africa had a very different focus than did an article that deconstructed law related to the trafficking of children on a global level. Common attributes among these diverse perspectives, however, were identified and include: (a) age, (b) vulnerability, (c) exploitation, and (d) violation of human rights (Bergman, 2011; Chung, 2009; Estes \& Weiner, 2001; Goździak 2008; Goldblatt Grace, Starck, Potenza, Kenney, \& Sjeetz, 2012; Howard, 2012; Kotrla, 2010; Logan \& Hunt, 2009; Miko \& Park, 2002; Smith, 2011).

\subsubsection{Age}

The United Nations' definition of child trafficking refers to anyone under the age of 18 (United Nations Crime and Information Justice Network, 2000). Demands in both the economic and sexual market for children result in recruitment strategies that play upon the child's lack of knowledge and access to external resources. Therefore, youth is considered an attribute of child trafficking (Chung, 2009; Estes \& Weiner, 2001; Fong \& Berger Cardoso, 2010; Goździak 2008; Goldblatt Grace et al., 2012; Jordan et al., 2013; Kotrla, 2010; Lalor, 2004; Logan \& Hunt, 2009; Miko \& Park, 2002).

\subsubsection{Vulnerability}

A highly important attribute is the vulnerability of victims of child trafficking (Howard, 2012). These children lacked resources for survival (i.e., money, shelter, food) and the knowledge, maturity, and abilities needed to keep themselves safe. Risk factors such as social immaturity, familial child abuse, running-away behaviors, physical immaturity, parental drug use, and a still-developing psychological disposition create a population of children who are highly susceptible to entering trafficking situations. These vulnerabilities contribute to a child's risk of being recruited or forced into an exploitive and abusive situation (Bergman, 2011; Estes \& Weiner, 2001; Fong \& Berger Cardoso, 2010; Goździak 2008, Howard, 2012; Lalor, 2004; Twill, Green, \& Traylor, 2010).

\subsubsection{Exploitation}

The literature yielded factors such as exploitation and economic profit for traffickers. Often, the exploitation of youth derived from corrupt political or police systems that either directly or indirectly profit from the market demand of children. This can be seen in cases of child sex tourism, which can be a large economic sector of a national economy (Smith, 2011). In addition, the culture of child sex trafficking often includes a highly coercive and manipulative relational component in the dynamics between children and their traffickers such that children feel emotionally tied and loyal to their pimps (Jordan et al., 2013). For parents, hopes and dreams of a better future for the child are easily exploited by traffickers (Smith, 2011).

\subsubsection{Violation of Human Rights}

Primary to the attributes of child trafficking is the violation of human rights. In the literature are references to the rights of children, such as the right to be protected from cruel acts and exploitation, to education, to be shielded from working conditions that hinder growth both physically and psychologically, and to be treated by the government or country as requiring special protections (United Nations Office of the High Commissioner for Human Rights, 2013). The literature also documented the existence of environments that consisted of subordination, excessively long working hours, hazardous working environments, physical and sexual violence and abuse, imprisonment, the absence of medical care, abuse by multiple perpetrators, and threats of violence to self and others that directly violated the specific human rights of children (Chung, 2009; Estes \& Weiner, 2001; Goździak 2008; Jordan et al., 2013; Logan \& Hunt, 2009).

\subsection{Antecedents}

Antecedents are events or qualities that precede the existence of the concept (Rodgers, 2000). This concept analysis revealed that the most commonly discussed antecedent was poverty, on both a global an individual-country basis. The factors that contribute to poverty include the marginalization of women and people of color and their lack in regard to income and other resources. In many cases, this resulted in a desperate need to consider alternative situations for their children that could provide for their most basic needs, such as domestic servitude in exchange for educational 
opportunities (Fong \& Berger Cardoso, 2010; Goździak 2008; Logan \& Hunt, 2009; Miko \& Park, 2002).

In the case of globalization, the vast number of children in need of income creates an easily accessible economic market for the trafficking of child labor, domestic servitude, and the profiting from child sex acts (Estes \& Weiner, 2001; Smith, 2011). Several articles concerned the existence of child trafficking as a result of the obvious demand of the child traffickers themselves, consisting of organized criminal groups, men who preferred sex with children, and businesses that demanded cheap labor (Jordan et al., 2013). In addition, various domestic, regional, and intercontinental trafficking situations prey upon the population of child runaways.

\subsection{Consequences}

In a concept analysis, consequences are the intended and unintended outcomes of the phenomenon being analyzed. Among the human rights violations present in child trafficking, the literature noted psychological, physical, and economic deprivations. Psychological effects included psychological trauma that resulted in post-traumatic stress disorder as well as depression, anxiety, and substance abuse problems for victims, thus creating a need for ongoing mental health interventions (Fong \& Berger Cardoso, 2010, Goździak 2008; Jordan et al., 2013). These psychological outcomes, also known as complex trauma, occur as the result of endured abuse that has occurred repeatedly and cumulatively over a period of time and within specific relational contexts (Courtois, 2004). The literature also included a focus on the role of healthcare providers in responding to the physical consequences of child trafficking, including sexually transmitted infections, unwanted abortions, and malnutrition (Fong \& Berger Cardoso, 2010; Goldblatt Grace et al., 2012). Further, the literature presented the diverse legal needs of children, created as a result of their trafficking histories, including protection by law enforcement, working legal definitions of child trafficking in societies where there were none, and special legal representation of children to advocate for their rights in fighting the abuses and exploitation that they have endured (Goździak, 2008).

Also seen in the literature were discussions of the macro- and mezzo-consequences of child trafficking. The authors focused on the specific human rights abuses and trauma imposed on the children rather than on the potential economic gain made by traffickers and governments actively involved in child trafficking.

\section{Discussion}

A majority of the works in this concept analysis focused on child trafficking and equated trafficking to the sex trafficking of children, while neglecting other forms of child trafficking, including hard labor, domestic servitude, and debt bondage (Chung, 2009; Fong \& Berger Cardoso, 2010; Goldblatt et al., 2012; Jordan et al., 2013; Kotrla, 2010; Smith, 2011). Whether this is the result of the particular databases or search terms that were chosen for this analysis is unknown but should be noted for future concept development in this area.

Much of the literature concerned child trafficking in its various forms, with a focus on the use of definitions to guide law, as represented in certain countries, in prosecuting trafficking acts or to combat the trafficking of children (Bergman, 2011; Chung, 2009; Fong \& Berger Cardoso, 2010; Kotrla, 2010; Lalor, 2004; Marcus, Riggs, Horning, Rivera, Curtis, \& Thompson, 2012; Miko \& Park, 2002; Smith, 2011). In addition, there was a focus on how particular legal frameworks and legal tools are utilized as well as their consequences. The law requires operationalized definitions of child trafficking and commonly uses phrases such as "use of threat, force, fraud or coercion and deception," as set forth in the definition of child trafficking by the United Nations, International Organization of Migration, and the International Labor Organization (Chung, 2009). Barriers to legal frameworks, particularly as related to child prostitution, also were discussed in the literature.

The literature also contained a description of trafficking on a spectrum of abuses or neglect, as originating from a variety of causes, and as resulting in a variety of political, economic, and personal consequences. Common to this literature was the reference to the detrimental effects of trafficking on the children themselves, resulting in both physical and psychological trauma, such as the transmission of HIV, malnutrition, depression, post-traumatic stress disorder, and substance abuse (Chung, 2009; Estes \& Weiner, 2001; Fong \& Berger Cardoso, 2010; Goldblatt Grace et al., 2012; Goździak 2008; Jordan et al., 2013; Lalor, 2004; Miko \& Park, 2002).

\subsection{Theoretical Definition}

As a result of the current concept analysis, the following theoretical definition of child trafficking was developed: Child trafficking is the specific exploitation of youth under the age of 18 years, initiated through force, fraud, coercion, deception, and the necessity for survival, and characterized by the violation of human rights, including physical, sexual, and psychological abuse, and the geographical movement of children. The promotion of the phenomenon is motivated by economic gain in which individuals, social networks, and countries profit monetarily. The origin of child trafficking stems from a surplus of individuals affected by poverty, globalization, the marginalization of women and children, and circumstances related to the destabilization of family units, which generally increases the vulnerability of children. 


\subsection{Implications}

Concept analyses have the capacity to generate further questions and identify future directions of inquiry (Rodgers \& Knafl, 2000). One of the leading functions of the concept analysis is to provide the foundation for which further investigation will take place. Field studies based upon a literature-based analysis would not only benefit from a baseline concept definition such as the one provided on child trafficking, they would continue to build on the definition from empirical evidence collected from heuristic efforts. In particular, the primary focus on child sex trafficking as a result of the current search conducted should be examined on a more in-depth level while working with data collection in the field. Further research could either verify the theoretical definition or add new information from a data-driven point of view.

\subsection{Limitations}

Based upon the nature of the analysis, including the search terms chosen and the narrowing of the timeframe, this study has certain limitations. Although other primary works within the field of child trafficking were added, it is possible that additional works that could have added to the analysis and subsequent findings were not included. In addition, the data collected were only that written in English, further limiting a potentially wider net of global information available.

\section{Summary}

This concept analysis was designed to further develop and define the concept of child trafficking through the use of Rodgers' (2000) evolutionary method of analysis. Through a discussion of surrogate terms, attributes, antecedents, and consequences, the current data analysis provides a holistic understanding of the uses, meanings, and actions associated with this concept. It is hoped that the concept of child trafficking will continue to be examined and used in the development of theory related to the causes, interventions designed to eradicate its occurrence, research and policy, and efforts to minimize its impacts within a diverse range of fields.

\section{References}

Baldwin, M. (2008). Concept analysis as a method of inquiry. Nurse Researcher, 15(2), 49-58. http://dx.doi.org/10.7748/nr2008.01.15.2.49.c6329

Bergman, A. (2011). For their own good? Exploring legislative responses to the commercial sexual exploitation of children and the Illinois Safe Children Act. Vanderbilt Law Review, 65(5), 1361-1400.

Botes, A. (2002). Concept analysis: Some limitations and possible solutions. Curationis, 25(3). http://dx.doi.org/10.4102/curationis.v25i3.779

Chung, R. (2009). Cultural perspectives on child trafficking, human rights \& social justice: A model for psychologists. Counseling Psychology Quarterly, 22(1), 85-96. http://dx.doi.org/10.1080/09515070902761230

Courtois, C. (2004). Complex trauma, complex reactions: Assessment and treatment. Psychotherapy: Theory, Research, Practice, Training, 41(4), 412-425. http://dx.doi.org/10.1037/0033-3204.41.4.412

Estes, R., \& Weiner, N. (2001) The commercial sexual exploitation of children in the United States, Canada and Mexico. Philadelphia, PA: University of Pennsylvania School of Social Work. http://dx.doi.org/10.3886/icpsr03366

Fong, R., \& Berger Cardoso, J. (2010). Child human trafficking victims: Challenges for the child welfare system. Evaluation and Program Planning, 33, 311-316. http://dx.doi.org/10.1016/j.evalprogplan.2009.06.018

Goldblatt Grace, L., Starck, M., Potenza, J., Kenney, P., \& Sjeetz, A. (2012). Commercial sexual exploitation of children and the school nurse. The Journal of School Nursing, 28(6), 410-417. http://dx.doi.org/10.1177/1059840512448402

Goździak, E., \& Collette, E. (2008). On challenges, dilemmas, and opportunities in studying trafficked children. Anthropological Quarterly, 81(4), 903-923. http://dx.doi.org/10.1353/anq.0.0033

Howard, N. (2012). A critical appraisal of anti-child trafficking discourse and policy and Southern Benin. Childhood, 19, 554-568. http://dx.doi.org/10.1177/0907568212444738

International Labor Organization. (2002). Every child counts: New global estimates on child labour. Retrieved from ILO website: http://www.ilo.org/ipecinfo/product/viewProduct.do?productId=742

Jordan, J., Patel, B., \& Rapp, L. (2013). Domestic minor sex trafficking: A social work perspective on misidentification, victims, buys, traffickers, treatment and reform of current practice. Journal of Human Behavior in the Social Environment, 23, 356-369. http://dx.doi.org/10.1080/10911359.2013.764198

Lalor, K. (2004). Child sexual abuse in Tanzania and Kenya. Child Abuse \& Neglect, 28, 833-844. http://dx.doi.org/10.1016/j.chiabu.2003.11.022 
Logan, T., Walker, R., \& Hunt, G. (2009). Understanding human trafficking in the United States. Trauma, Violence, \& Abuse, 10(1), 3-30. http://dx.doi.org/10.1177/1524838008327262

Marcus, A., Riggs, R., Horning, A., Rivera, S., Curtis, R., \& Thompson, E. (2012). Is child to adult as victim is to criminal? Social policy and street-based sex work in the USA. Sex Research and Social Policy, 9, 153-166. http://dx.doi.org/10.1007/s13178-011-0070-1

Miko, F., \& Park, G. (2002). Trafficking in women and children: The U.S. and international response. Washington, DC: Congressional Research Service.National Conference of State Legislatures. (2014). Retrieved from:http://www.ncsl.org/research/civil-and-criminal-justice/human-trafficking-overview.aspx

Rodgers, B. L. (2000). Concept analysis: An evolutionary view. In B. L. Rodgers \& K. A. Knafl (Eds.), Concept development in nursing: Foundations, techniques, and applications, 77-102. Philadelphia, PA: Saunders.

Smith, H. (2011). Sex trafficking: Trends, challenges, and the limitations of international law. Human Rights Review, 12, 271-286. http://dx.doi.org/10.1007/s12142-010-0185-4

Twill, S., Green, D., \& Traylor, A. (2010). A descriptive study on sexually exploited children in residential treatment. Child \& Youth Care Forum, 39, 187-199. http://dx.doi.org/10.1007/s10566-010-9098-2

United Nations Crime and Information Justice Network. (2000). Protocol to prevent, suppress, and punish trafficking in persons, especially women and children, supplementing the United Nations Convention Against Transnational Organized Crime. Retrieved from UNCIJN website: http://www.uncjin.org/Documents /Conventions/dcatoc/final_documents_2/convention_\%20traff_eng.pdf

United Nations Office of the High Commissioner for Human Rights. (2013). Convention on the rights of the child. Retrieved from http://www.ohchr.org/en/professionalinterest/pages/crc.aspx

\section{(cc) $\mathrm{EY}$}

This work is licensed under a Creative Commons Attribution 3.0 License. 